\title{
MESIN DWI FUNGSI PENCETAK PELET IKAN DENGAN MENGGUNAKAN MOTOR TUNGGAL
}

\author{
Rita Juliani ${ }^{1}$, Friscylia Tampubolon ${ }^{2}$, Sri Ratika Samosir ${ }^{3}$, \\ Mariana Simangunsong ${ }^{4}$, Laurenchus Manurung ${ }^{5}$ \\ ${ }^{1,2,3)}$ Jurusan Fisika, FMIPA, Universitas Negeri Medan, \\ ${ }^{4)}$ Jurusan Biologi, FMIPA, Universitas Negeri Medan, \\ ${ }^{5}$ Jurusan Elektro, Fakultas Teknik, Universitas Negeri Medan, \\ Jl. Willem Iskandar pasar V-Kotak Pos No. 1589-Medan 20221 \\ e-mail: julianiunimed@gmail.com
}

\begin{abstract}
Abstrak
Telah di lakukan pembuatan mesin dwi fungsi pencetak pelet di desa Harean Porsea yang bertujuan membantu masyarakat peternak ikan dalam memproduksi pellet dari limbah jerami padi. Metode yang digunakan di mulai dari rancangan atau desain, penyediaan alat dan bahan yang di lanjutkan dengan pembuatan serta uji coba mesin. Hasil yang diperoleh mesin dwi fungsi pencetak pellet telah bekerja secara maksimal dengan jumlah rata-rata produksi pelet $6 \mathrm{~kg} / \mathrm{jam}$ dan mesin dwi fungsi memiliki mesin penggerak yang dapat berfungsi sebagai pencacah jerami, penghalus keong mas dan produksi pelet.
\end{abstract}

Kata Kunci : Mesin, Pelet, Produksi, Harean

\begin{abstract}
Has done machine fabrication dwi function printer pellets in the village Harean Porsea which aims to help fish farmers in producing pellets from rice straw waste. Methods used in starting from a design, provision of tools and material in continue with to prepare and pellet machine. The results machine dwi function printer pellets have been working maximally by the number of on average production pellets $6 \mathrm{~kg}$ per hour and machine dwi function having the engine propulsion that can serve as enumerators straw, smoothing keong mas and production pellets.
\end{abstract}

Keywords : machine, pellet, production, Harean

\section{Pendahuluan}

Masyarakat desa Harean di Kecamatan Porsea tinggal di pinggiran Danau Toba dan kaki gunung Bukit Barisan dengan mata pencaharian sebagian besar sebagai petani padi dan usaha sampingan bertani ikan mas. Hasil panen padi setiap tahun memproduksi limbah jerami yang kurang termanfaatkan (Marta 2003).
Salah satu pendorong kurang termanfaatkan limbah jerami adalah minimnya pengetahuan masyarakat dan cara mengolah jerami padi serta ketidak tersediaan alat. Permasalahan masyarakat Harean oleh TIM di cari solusi atau penyelesaian dengan menerapkan teknologi sederhana dan termanfaatkan berupa alat pengolahan jerami menjadi pellet ikan yang dapat mengatasi limbah jerami dan termanfaatkannya menjadi pellet ikan bagi petani (Awaluddin, 2010). 
Alat yang di desain adalah mesin pellet yaitu mesin dwi fungsi yang digunakan untuk mengolah dan memproduksi pellet atau pakan ikan. Teknologi hasil inovasi membua tmesin dengan rancangan dua fungsi dalam satu mesin yaitu mesin pembuatan tepung dari keong mas dan mesin penghalus jerami serta pencetak pelet. Produksi mesin yang di hasilkan akan membantu masyarakat dalam pembuatan pakan ikan mas menjadi lebih mudah (Sarwono, dan Arianto 2003)..

\section{Bahan dan Metode}

Bahan yang di gunakan dalam pembuatan mesin pellet adalah gearbox, motor $750 \mathrm{KW}$, plat baja $4 \times 4$ tebal $4 \mathrm{~mm}$, plat besi, poli, tali poli, as, tabung besi. Alat yang digunakan berupa grenda, bor, las, mesin bubut (Anonim, 2016).

Metode yang digunakan di mulai dari rancangan atau desain, penyediaan alat dan bahan yang di lanjutkan dengan pembuatan serta ujicoba mesin.

\section{Hasil dan Pembahasan}

\section{Rancangan Mesin}

Rancangan mesindi lakukan dengan menggunakan software autocad yang mempermudah dalam perancangan pembuatan mesin. Desain yang dibuat menggabungkan dua luaran yang berbeda dalam satu motor listrik $1400 \mathrm{rpm}$ sehingga dapat menghemat penggunaan motor.

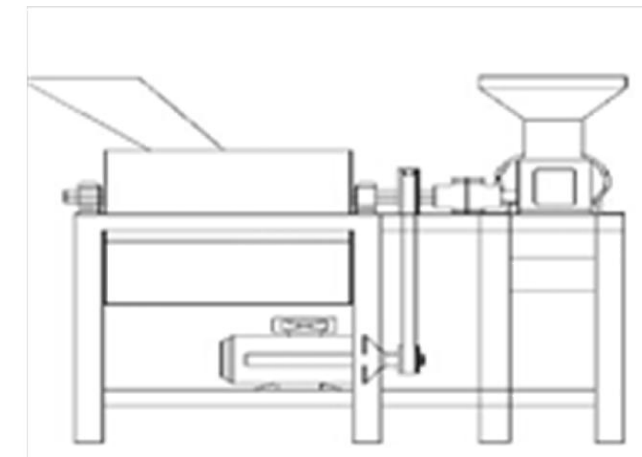

Gambar 1.a. Tampak mesin dari depan
Desain yang di buat berupa mesin pencacah jerami dan tepung keong mas dengan dimensi : T.80 X L.29 X P.68 cm. Desain pencetak pellet dengan dimensi: T.80 X L.18 X P.69 cm Gambar anrancangan untuk tampak depan di perlihatkan pada (Gambar 1a), dan belakang (Gambar 1b) sertaatas (Gambar 1c).

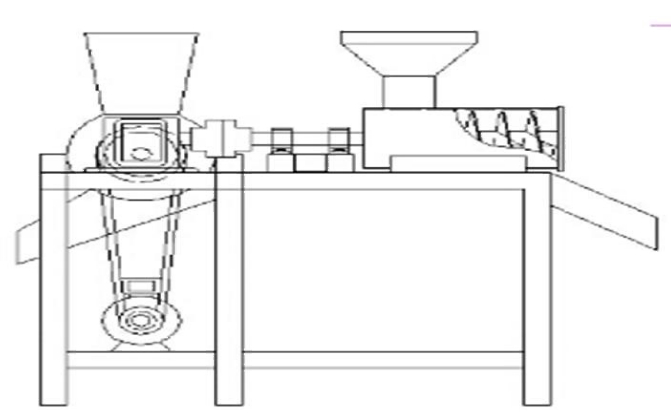

Gambar 1.b. Tampak Belakang

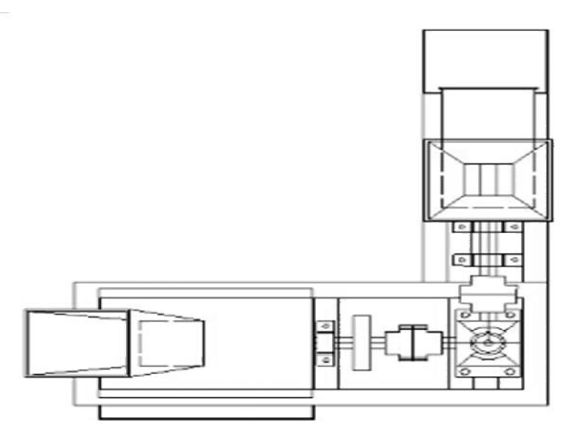

Gambar 1.c. Tampak Atas

\section{Pembuatan Mesin}

Pembentukan alat di mulai dari penyediaan alat dan bahan (Gambar 2) dan di lajuti dengan pembuatan rangka dari plat baja siku 4 x 4 tebal $4 \mathrm{~mm}$ sesuai ukuran sebagai kerangka dudukan. 


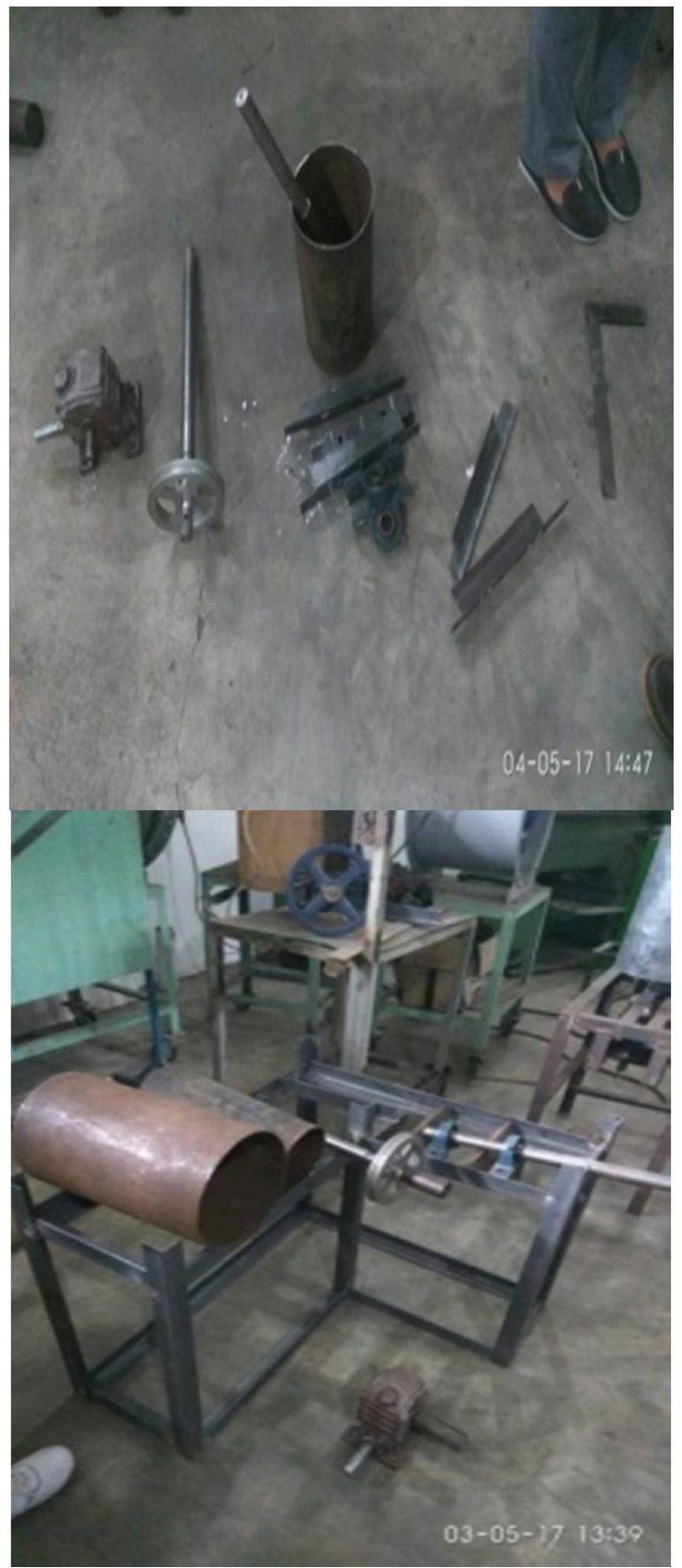

Gambar 2. Alat dan bahan

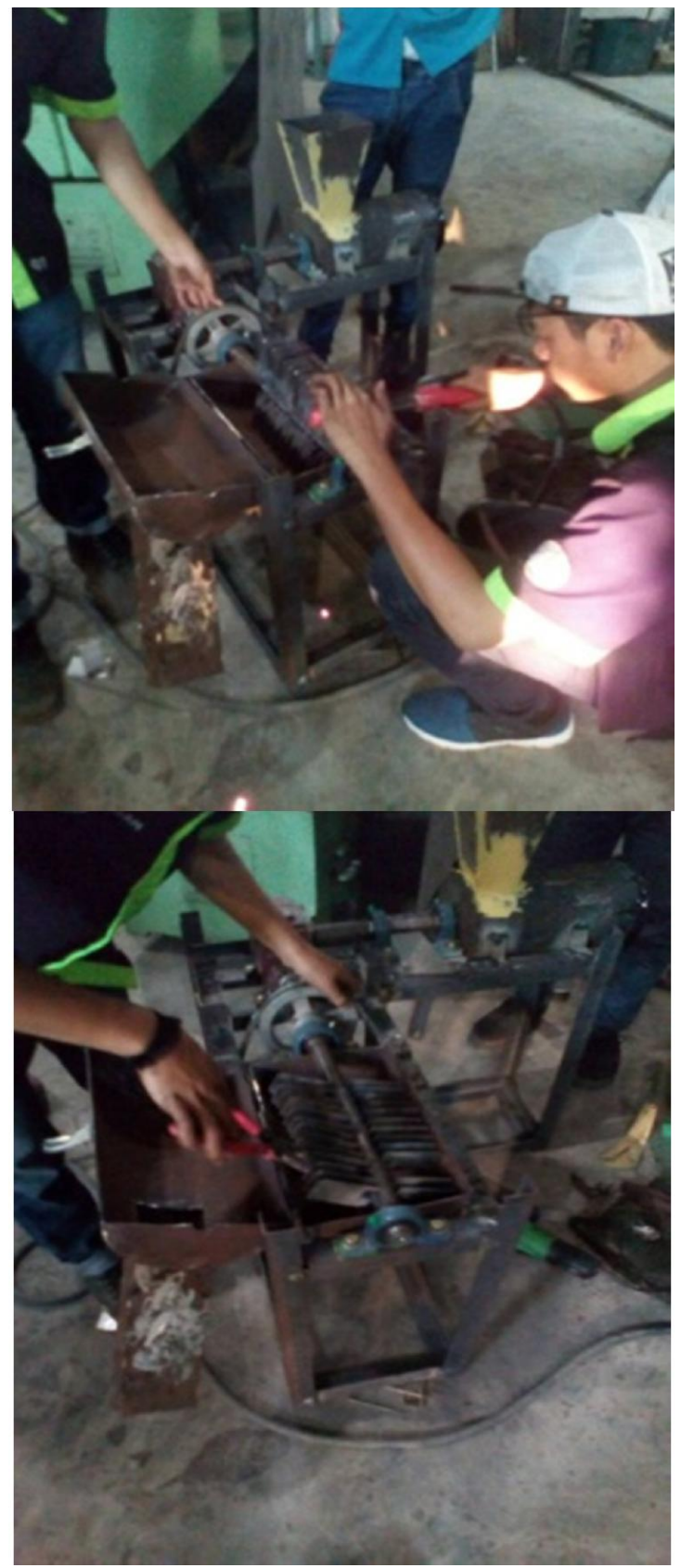

Gambar 3. Proses pembentukan mesin

\section{Mesin pelet}

Proses pembuatan kerangka dan penggabungan mesin pencacah dan pembuat pellet selesai dilanjutkan dengan finishing yaitu pengecatan (Gambar 4) Mesin pelet telah siap untuk di gunakan dengan dwi fungsi yaitu masukan (input) pertama tempat pengolahan jerami yang akan dihaluskan berikut keong mas. Input kedua tempat masukan adonan pelet yang akan dicetak. 


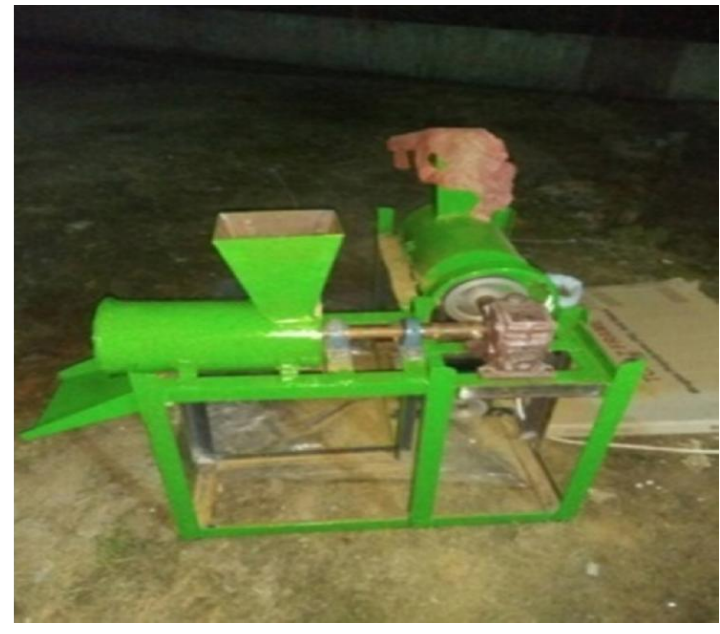

Gambar 4. Pengecatan mesin pelet

\section{Ujicoba alat}

Mesin dwi fungsi pencetak pelet di uji coba terlebih dahulu untuk mencacah jerami hingga berbentuk tepung yang bermanfaat pada pencampuran adonan pelet.

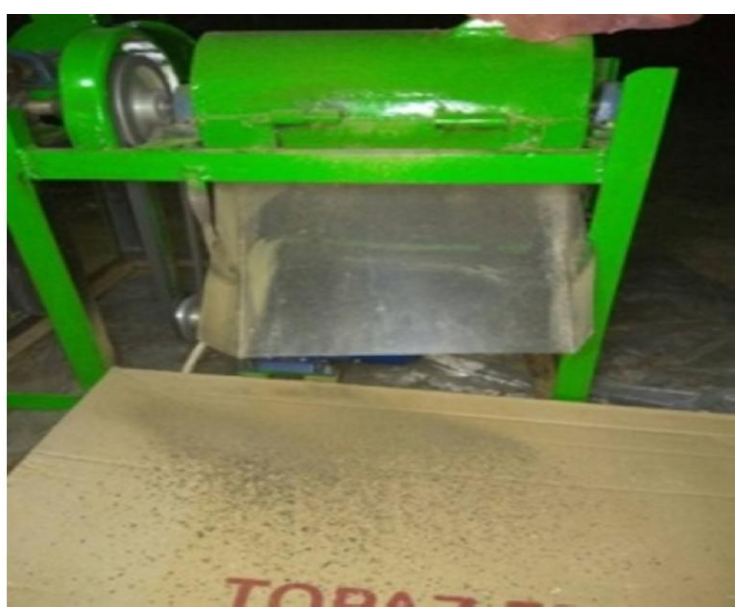

Gambar 5. Mencacah Jerami

Gambar 5 menunjukkan bahwa mesin sedang mencacah jerami. Hasil yang di peroleh, jerami menjadi lebih halus begitu juga dengan keong mas. Fungsi kedua dari mesin adalah untuk mencetak pelet. Mesin pencetak pelet menghasilkan pelet terbentuk butiran.

Hasil pengujian mesin diperoleh data padaTabel 1.
Tabel 1. Produksi mesin pencacah jerami

\begin{tabular}{|c|c|c|c|}
\hline No & Jenis Mesin & rpm & $\begin{array}{l}\text { Produksi } \\
\text { Kg/jam }\end{array}$ \\
\hline 1 & $\begin{array}{l}\text { Putaran } \\
\text { Pencetak } \\
\text { Pelet }\end{array}$ & 60 & 6 \\
\hline 2 & $\begin{array}{l}\text { Putaran } \\
\text { Pencacah } \\
\text { jerami dan } \\
\text { keong mas }\end{array}$ & 600 & $3.5-6$ \\
\hline
\end{tabular}

Hasil memperlihatkan bahwa pencacah jerami memproduksi $3.5 \mathrm{~kg} / \mathrm{jam}$ dengan hasil keluaran tepung jerami. Untuk keong mas memproduksi $6 \mathrm{~kg} / \mathrm{jam}$ dengan luaran berupa tepung keong mas. Pencetak pellet menghasilkan pelet $6 \mathrm{~kg} /$ jam dalam bentuk produksi butiran memanjang.

\section{Kesimpulan dan Saran}

Berdasarkan hasil penelitian ini, maka dapat disimpulkan yaitu:

1. Mesin dwi fungsi pencetak pellet telah bekerja secara maksimal dengan jumlah rata-rata produksi pelet $6 \mathrm{~kg} / \mathrm{jam}$

2. Mesin dwi fungsi memiliki mesin penggerak yang dapat berfungsi sebagai pencacah jerami, penghalus keong mas dan produksi pelet.

\section{Ucapan Terima Kasih}

TIM mengucapkan terimakasih kepada RISTEKDIKTI yang mendanai kegiatan PKM-T, Bapak Rektor Universitas Negeri Medan dan jajarannya, masyarakat peternak ikan mas desa Harean Porsea, yang berpartisipasi, kepala bengkel Fakultas Teknik Universitas Negeri Medan yang telah bekerja sama dengan TIM didalam pembuatan teknologi mesin dwi fungsi serta kepada ibu Dosen Pendamping yang telah membimbing terlaksananya kegiatan, dan buat semua pihak yang telah mendukung. 


\section{Daftar Pustaka}

Anonim, 2016. Rumah mesin pellet https://www.rumahmesin.com/produk/m esin-pelet-ikan/

Awaluddin, 2010. Sistem Integrasi PadiTernak, Balai Pengkajian Teknologi Pertanian (BPTP) Sulawesi Selatan, Makassar, [Kamis, 20 Oktober 2011].

Marta W. U., 2003. Pemanfaatan Jerami Padi Sebagai Pengganti Rumput Untuk Ternak Ruminansia Kecil, Wartazoa Vol. 13 No. 3 Th. 2003.

Sarwono, W., \& Arianto, 2003. Manajemen Pemeliharaan Sapi Potong. Penebar Swadaya, Jakarta. 